\title{
Neuroleptic-induced Parkinson's syndrome: clinical features and results of treatment with levodopa
}

\author{
R J HARDIE, A J LEES \\ From the National Hospital for Nervous Diseases, London, UK
}

SUMMARY Twenty six consecutive patients with neuroleptic-induced Parkinson's syndrome (NIPS) are described. Their median age was 61 years, $60 \%$ were female, and most had received chronic neuroleptic medication for psychiatric indications. The clinical features were indistinguishable from idiopathic Parkinson's disease, except for the presence of co-existing orofacial chorea, limb dyskinesia or akathisia which provided an aetiological clue in 11 cases. Complete resolution of NIPS occurred in only two patients, one of whom later developed Parkinson's disease. Sixteen patients were treated with 300-1000 mg levodopa/benserazide for up to 4 years with few adverse effects but therapeutic response was disappointing.

It is widely recognised that neuroleptic drugs can induce a state of Parkinsonism, a major adverse reaction attributed to antagonism at striatal dopamine receptors. In one of the largest series, Ayd $^{1}$ reported an overall incidence of $15 \%$ for neuroleptic-induced Parkinson's syndrome (NIPS) in over 3700 patients, and more recent experience has suggested a prevalence of up to $40 \% .^{23}$ It is important to distinguish between the prevalence of extra-pyramidal signs and actual morbidity attributable to the medication ${ }^{34}$ but there can be no doubt that NIPS causes significant functional disability in some cases.

There is no generally accepted agreement regarding management. Relapse rates are higher amongst schizophrenic patients if anti-psychotic treatment is withdrawn, hence chronic maintenance therapy is warranted in many cases. ${ }^{56}$ The value of anticholinergic drugs has probably been over-estimated, particularly when administered routinely, ${ }^{2-4}$ and there is some evidence to suggest that NIPS may remit spontaneously even when the neuroleptic drug is continued, perhaps because of delayed receptor supersensitivity. ${ }^{7}$

The effects of levodopa have seldom been examined in NIPS despite a few encouraging reports. ${ }^{8-10}$ This may partly reflect assumptions about competitive an-

Address for reprint requests: Dr A Lees, The National Hospital for Nervous Diseases, Queen Square, London WCIN 3BG, UK.

Received 9 September 1987 and in revised form 5 February 1988. Accepted 16 February 1988 tagonism between the two forms of drug treatment and also fears concerning exacerbation of psychosis, ${ }^{1112}$ although we and others ${ }^{1314}$ have safely used levodopa in psychiatric illness in attempts to ameliorate tardive dyskinesia. Because of ethical and safety considerations in an outpatient population with mainly psychiatric illness, a double-blind placebocontrolled study would have been difficult to justify and to carry out. We therefore devised an open pilot study to assess the safety and possible efficacy of levodopa given in combination with benserazide.

The present report summarises the clinical features of a group of patients believed to have NIPS, and describes the results of various management strategies including the use of levodopa.

\section{Patients and Methods}

We reviewed 26 consecutive patients (16 female, 10 male) aged 21-79 years (median 61) referred over a 3-year period to a neurologist because of Parkinsonian features that were considered likely to be secondary to drug treatment. The review was partly retrospective, but over half the patients were followed prospectively from initial presentation. Their clinical details are shown in table 1 . Most had a diagnosis of schizophrenia or schizo-affective disorder treated with a variety of anti-psychotic agents (usually two or more); two were elderly women with vertigo. Four (JC, HS, KS, HY) had recieved electro-convulsive therapy in the past, but none had undergone neurosurgical procedures.

A detailed drug history was obtained using the records of general practitioners and the Community Psychiatric Nursing Services as well as hospital case notes. 
Table 1 Clinical details of patients

\begin{tabular}{|c|c|c|c|c|c|c|c|c|}
\hline$P t$ & Sex & Age & Diagnosis & Drugs & Duration & $W W$ & $A$ & Other \\
\hline $\begin{array}{l}\text { JS } \\
\text { PM } \\
\text { AN } \\
\text { PW } \\
\text { NW } \\
\text { JC } \\
\text { TM } \\
\text { CR } \\
\text { CT } \\
\text { KG } \\
\text { HS } \\
\text { ON } \\
\text { GP } \\
\text { JD } \\
\text { GT } \\
\text { AB } \\
\text { RB } \\
\text { AD } \\
\text { HY } \\
\text { LC } \\
\text { ES } \\
\text { AS } \\
\text { MC } \\
\text { KS } \\
\text { JK } \\
\text { AK }\end{array}$ & $\begin{array}{l}\mathbf{M} \\
\mathbf{M} \\
\mathbf{F} \\
\mathbf{M} \\
\mathbf{F} \\
\mathbf{F} \\
\mathbf{F} \\
\mathbf{F} \\
\mathbf{F} \\
\mathbf{F} \\
\mathbf{M} \\
\mathbf{F} \\
\mathbf{M} \\
\mathbf{M} \\
\mathbf{M} \\
\mathbf{F} \\
\mathbf{M} \\
\mathbf{F} \\
\mathbf{M} \\
\mathbf{F} \\
\mathbf{F} \\
\mathbf{F} \\
\mathbf{F} \\
\mathbf{F} \\
\mathbf{M} \\
\mathbf{F}\end{array}$ & $\begin{array}{l}21 \\
46 \\
52 \\
52 \\
53 \\
55 \\
56 \\
56 \\
58 \\
60 \\
61 \\
61 \\
61 \\
61 \\
61 \\
64 \\
66 \\
70 \\
72 \\
74 \\
74 \\
75 \\
76 \\
76 \\
77 \\
79\end{array}$ & $\begin{array}{l}\text { schizophrenia } \\
\text { depression } \\
\text { schizo-affective } \\
\text { depression } \\
\text { schizophrenia } \\
\text { depression } \\
\text { schizo-affective } \\
\text { schizophrenia } \\
\text { schizo-affective } \\
\text { Korsakoff } \\
\text { schizophrenia } \\
\text { schizophrenia } \\
\text { schizophrenia } \\
\text { schizophrenia } \\
\text { schizophrenia } \\
\text { schizo-affective } \\
\text { hypomania } \\
\text { bipolar affective } \\
\text { agitated depression } \\
\text { vertigo } \\
\text { schizo-affective } \\
\text { vertigo } \\
\text { schizophrenia } \\
\text { schizo-affective } \\
\text { agitated depression } \\
\text { schizo-affective }\end{array}$ & $\begin{array}{l}\text { CPZ HPL } \\
\text { FPZ* } \\
\text { TRZ FPX* } \\
\text { FPX } \\
\text { FPZ* PTZ* } \\
\text { CPZ TRZ HPL* } \\
\text { CPZ FPX** } \\
\text { FPZ* TFP FPX } \\
\text { TRZ } \\
\text { CPZ FPZ } \\
\text { TFP FPX* TRZ } \\
\text { TFP FPZ* } \\
\text { FPZ* FPX* } \\
\text { CPZ FPZ* } \\
\text { CPZ FPX* } \\
\text { FPX } \\
\text { CPZ HPL } \\
\text { CPZ TFP } \\
\text { PIM TRZ } \\
\text { PCP } \\
\text { PFZ TRZ } \\
\text { PFZ } \\
\text { FPZ* } \\
\text { TRZ } \\
\text { CPZ } \\
\text { PIM }\end{array}$ & $\begin{array}{l}4 \mathrm{w} \\
12 \mathrm{~m} \\
6 \mathrm{~m} \\
7 \mathrm{y} \\
2 \mathrm{y} 6 \mathrm{~m} \\
6 \mathrm{y} \\
2 \mathrm{y} 6 \mathrm{~m} \\
3 \mathrm{y} 6 \mathrm{~m} \\
6 \mathrm{y} \\
11 \mathrm{~m} \\
20 \mathrm{y} \\
3 \mathrm{~m} \\
9 \mathrm{y} \\
19 \mathrm{y} \\
8 \mathrm{~m} \\
3 \mathrm{y} \\
17 \mathrm{y} \\
9 \mathrm{y} \\
3 \mathrm{y} \\
7 \mathrm{~m} \\
3 \mathrm{y} \\
22 \mathrm{y} \\
11 \mathrm{y} \\
12 \mathrm{y} \\
6 \mathrm{w} \\
2 \mathrm{y}\end{array}$ & $\begin{array}{l}\text { TRB } \\
\text { RB } \\
\text { R } \\
\text { T } \\
\text { T } \\
\text { TR } \\
\text { TRB } \\
\text { TR } \\
\text { R } \\
\text { T } \\
\text { B } \\
\text { TRB } \\
\text { RB } \\
\text { R } \\
\text { TR } \\
\text { RB } \\
\text { TR } \\
\text { RG } \\
\text { B } \\
\text { R } \\
\text { RBG } \\
\text { TRBG } \\
\text { TRB } \\
\text { BG } \\
\text { BG } \\
\text { TB }\end{array}$ & $\begin{array}{l}+ \\
- \\
+ \\
+ \\
++ \\
+ \\
+ \\
+ \\
+ \\
+ \\
+ \\
+ \\
+ \\
+ \\
+ \\
+ \\
+ \\
+ \\
+ \\
+ \\
+ \\
+ \\
+\end{array}$ & $\begin{array}{l}\text { DT } \\
\text { OD AK } \\
\text { OD } \\
\text { OD AK } \\
\text { LD AK } \\
\text { OD } \\
\text { OD } \\
\text { OD } \\
\text { OD } \\
\text { OD } \\
\text { OD LD } \\
\text { OD LD } \\
\text { LD } \\
\text { AK } \\
\text { - } \\
\text { - } \\
\text { - } \\
\text { - } \\
\text { LD }\end{array}$ \\
\hline
\end{tabular}

Drugs: chlorpromazine CPZ; haloperidol HPL; fluphenazine FPZ; flupenthixol FPX; perphenazine PFZ; pimozide PIM; pipothiazine PTZ; thioridazine TRZ; trifluoperazine TFP; *denotes depot preparation.

WW = worst Webster score: tremor T; rigidity R; bradykinesia B; gait G.

$\mathbf{A}=$ asymmetry in at least 2 items of the Webster score.

Other features: orofacial dyskinesia OD; limb dyskinesia LD; akathisia AK; dystonia DT.

Extra-pyramidal features on clinical examination were assessed using the Webster rating scale, ${ }^{15}$ and functional disability recorded using the Northwestern University Disability Scale (NUDS). ${ }^{15}$ The distribution and severity of any dyskinesia was also recorded.

Twenty one patients in whom Parkinsonism was causing significant disability were identified for further management. Where possible, the dopamine receptor antagonist was gradually withdrawn, under joint supervision with psychiatric colleagues if appropriate. In those who did not improve, or in those whose psychiatric illness was considered too unstable to permit withdrawal, a trial of anti-Parkinsonian medication was given. Provided that tardive dyskinesia and akathisia were absent or only mild, the dosage of any existing anti-cholinergic drug was increased to maximum tolerated levels, or benzhexol introduced in doses increasing to 8 mg daily. If anti-cholinergic drugs were ineffective or contraindicated, treatment with levodopa + benserazide ("Madopar") was gradually introduced and the dosage cautiously increased at monthly intervals according to clinical response. Patients were examined on each attendance by one of the authors.

\section{Results}

\section{Clinical observations at presentation (table 1)}

The median age of our patient group was 61 years, with a very variable duration of exposure to neuroleptic drugs between 4 weeks and 22 years (median 3 yr, mean $6.3 \mathrm{yr}$ ).

Those Parkinsonian features (one or more) which were scored highest in each patient at presentation were rigidity in 18 patients, bradykinesia in 14 , tremor in 13 and gait in five. The signs were asymmetrical in 14. Oro-facial or limb dyskinesia was present in 11 cases. There was no obvious correlation between age and dosage or duration of drug exposure.

\section{Management}

Three patients (CT, JD, GP) were considered to be asymptomatic and not sufficiently incapacitated to warrant intervention. Two (AB, RB) had mild Parkinsonism but severe tardive dyskinesia in addition, which was felt to be the more disabling problem. They were both managed by substitution of sulpiride for the offending drug with some improvement of both problems, and were excluded from further analysis.

The remaining 21 patients had Parkinsonism causing sufficient disability to warrant therapeutic intervention. In five of these the psychiatric condition was too unstable to permit safe withdrawal of the offending drugs. Addition of benzhexol in the two patients (ON, KG) not already taking an anticholinergic was without benefit, and all five received a trial of levodopa.

The offending drug was withdrawn in 16 patients. In one (HY), the Parkinsonian features resolved rapidly and completely over 4 months and he remained well when followed up over the next 3 years. One patients (HS) suffered a relapse of his schizophrenic 
illness within 3 months and, over the following 2 years until his death, continued to have disabling symptoms from both his psychiatric condition and its treatment.

Anti-Parkinsonian medication was given to the other 13 patients. Five of these were already receiving "prophylactic" anti-cholinergic agents, increased dosage of which achieved adequate symptom control in two (TD, PM). A trial of benzhexol was without effect in four other patients (AN, JC, JS, PW), one of whom (JC) died shortly afterwards from an unrelated condition, and so the effect of levodopa was examined in 11 cases with continued disabling Parkinsonism despite withdrawal of the offending drug.

The results in 15 patients treated with $300-1000 \mathrm{mg}$ levodopa daily for up to 4 years are shown in table 2 . Response to levodopa was graded according to percentage improvement in baseline Webster score as: none $(<20 \%)$, slight $(20-40 \%)$, moderate $(41-75 \%)$, or complete if the Webster score fell below 4 . Similar changes were seen on the NUDS which are not included in the table. One further patient (LC) with intractable vertigo committed suicide within 3 months of the start of treatment, which was not thought to be relevant to her death, and response could not adequately be assessed. One patient (PW) received levodopa after an unsuccessful trial of benzhexol for 2 months because of incapacitating tremor and akinesia. His Parkinsonism resolved completely within the next 3 months, only to re-appear 12 months after discontinuation.

Apart from an exacerbation of agitated anxiety in one case (AK), there was no deterioration in psychiatric state associated with levodopa therapy. Dose-limiting involuntary dyskinesia in 2 cases (AD, CR) was the only other adverse effect.

\section{Discussion}

It may sometimes be difficult to distinguish between the motor disorder of severe psychiatric illness itself, notably catatonic schizophrenia, and true Parkinsonism ${ }^{1617}$ whether induced by anti-psychotic drugs or due to concurrent idiopathic nigrostriatal degeneration with Lewy bodies, that is, Parkinson's disease. Symmetry of extrapyramidal signs, absence of tremor and reversibility are all said to be typical of NIPS rather than Parkinson's disease. ${ }^{18}$ However, it is increasingly recognised that some cases may not completely resolve following drug withdrawal, and underlying Parkinson's disease is then suspected.

Apart from the lack of young subjects, which probably reflects referral bias, the age distribution of our patients was the same as that observed by Ayd. ${ }^{1}$ Thus prevalence rates increased directly in proportion to age within the range $40-80$ years, exactly as for Parkinson's disease. The excess of females is well established for NIPS ${ }^{1}$ and remains unexplained, although it is not seen in Parkinson's disease. An oestrogen effect has been postulated. The high mortality rate $(12 \%)$ amongst our patients reflects their age.

Furthermore, the clinical features of our patientso were indistinguishable from Parkinson's disease, including a high proportion with asymmetrical signs. 0 Like Stephen and Williamson, ${ }^{19}$ we also found many with tremor, with $53 \%$ having symptomatic tremor of greater or equal severity to other cardinal signs. In-o deed the only distinctive features were the presence of (tardive) dyskinesia and/or akathisia in 15 caseso $(60 \%)$. This would be a valuable pointer to the aetiology of a Parkinsonian syndrome when the drug

Table 2 Patients treated with levodopa

\begin{tabular}{|c|c|c|c|c|c|c|}
\hline \multirow[b]{2}{*}{ Patient } & \multicolumn{2}{|c|}{ Webster score } & \multicolumn{4}{|c|}{ Duration (months) of levodopa } \\
\hline & Pre/post & Response & Delay & Treatment & Follow up & Dose $m g$ \\
\hline $\begin{array}{l}\text { Drug withdrawn } \\
\text { CR } \\
\text { KS } \\
\text { AK } \\
\text { AN } \\
\text { ES } \\
\text { AD } \\
\text { JK } \\
\text { AS } \\
\text { JS } \\
\text { PW }\end{array}$ & $\begin{array}{l}12 / 10 \\
15 / 16 \\
10 / 6 \\
22 / 17 \\
26 / 18 \\
11 / 4 \\
14 / 8 \\
11 / 3 \\
23 / 0 \\
13 / 2\end{array}$ & $\begin{array}{l}\text { none } \\
\text { none } \\
\text { slight } \\
\text { slight } \\
\text { slight } \\
\text { moderate } \\
\text { moderate } \\
\text { moderate } \\
\text { complete } \\
\text { complete† }\end{array}$ & $\begin{array}{l}0 \\
0 \\
1 \\
4 \\
3 \\
0 \\
0 \\
2 \\
1 \\
1\end{array}$ & $\begin{array}{r}29 \\
3 \\
7 \\
30 \\
9 \\
2 \\
21 \\
39 \\
24 \\
6\end{array}$ & $\begin{array}{r}30 \\
3 \\
15 \\
30 \\
10 \\
30 \\
21 \\
39 \\
24 \\
23\end{array}$ & $\begin{array}{c}1000^{*} \\
600 \\
300^{*} \\
600 \\
600 \\
1000^{*} \\
300 \\
150 \\
300 \\
300\end{array}$ \\
\hline $\begin{array}{l}\text { Drug continued } \\
\text { NW } \\
\text { MC } \\
\text { KG } \\
\text { GT } \\
\text { ON }\end{array}$ & $\begin{array}{l}10 / 11 \\
15 / 15 \\
20 / 15 \\
23 / 14 \\
18 / 6\end{array}$ & $\begin{array}{l}\text { none } \\
\text { none } \\
\text { slight } \\
\text { moderate } \\
\text { moderate }\end{array}$ & $\begin{array}{l}- \\
- \\
-\end{array}$ & $\begin{array}{r}12 \\
6 \\
47 \\
33 \\
26\end{array}$ & $\begin{array}{l}28 \\
12 \\
53 \\
33 \\
26\end{array}$ & $\begin{array}{c}800^{*} \\
800^{*} \\
1000^{*} \\
800 \\
300\end{array}$ \\
\hline
\end{tabular}

Excludes one unrelated death $\mathrm{LC}$.

*denotes levodopa later discontinued (AD because of AIMs, ES during intercurrent infection from which she succumbed, AK because of increased anxiety, others lack of convincing response).

†PW developed Parkinsonism again 12 months after levodopa therapy was discontinued. 
history is uncertain or not available and when there is no previous history of psychotic illness.

Twenty one $(81 \%)$ of our patients were under psychiatric supervision and the aetiology of their Parkinsonism was obvious in all, but this may not always be the case. Dopamine receptor antagonists with non-psychiatric indications such as prochlorperazine, metoclopramide, cinnarizine and flunarizine can all induce secondary Parkinsonism, ${ }^{19-23}$ yet may be overlooked. Indeed, in the recent community survey of Parkinson's disease in Aberdeen, ${ }^{24} 18 \%$ of all cases initially ascertained as having idiopathic Parkinson's disease were subsequently rejected as NIPS and in another report half of all new referrals to a geriatric department with Parkinsonism were believed to have NIPS. ${ }^{19}$

The management of NIPS remains largely empirical. Obviously the best course is withdrawal of the offending drug as soon as the complication is identified. Chronic administration of anti-emetics or vestibular sedatives is very seldom warranted. The dose of neuroleptic drugs can often be reduced after control of an acute psychotic illness is established, and the indications for maintenance treatment should be continually reviewed. However, there are many patients in whom drug therapy cannot be safely discontinued. Furthermore, drugs of this class typically have cumulative effects even if depot formulations are not used and the severity of the syndrome may be sufficient to require urgent intervention.

Traditionally, anti-cholinergic agents have been used either as prophylaxis against NIPS or in its management. Surprisingly, there is little evidence of their efficacy. Thus few psychiatric patients show any deterioration in their Parkinsonism following withdrawal of existing anti-cholinergic drugs, ${ }^{24}$ and in some of these the deterioration may be only technically rather than functionally relevant. ${ }^{3} \mathrm{~A}$ variety of important complications have been recognised ${ }^{7}$ and many authorities have concluded that these agents have only a very limited role. ${ }^{34}$

Clinical trials in this area are notoriously difficult to conduct and interpret, ${ }^{7}$ but in at least one doubleblind study amantadine and orphenadrine were not superior to placebo. ${ }^{26}$ Moreover, in some of the early double-blind, placebo-controlled trials establishing the value of maintenance therapy with neuroleptics, "blind" psychiatrists were free to prescribe anticholinergic medication which they did equally amongst the placebo and active treatment groups. ${ }^{252728}$ This confirms the subjective nature of perceived extra-pyramidal features in patients with often severe psychiatric illness which may have its own concomitant motor disorder. ${ }^{17}$

Beneficial changes in mental state have been claimed with levodopa administered to psychiatric pa- tients in low doses. ${ }^{29-31}$ This may in part be due to non-specific alerting effects since larger doses have been associated with an increased frequency of psychotic features. ${ }^{111232-3}$ There are few reports of the use of levodopa in NIPS, and only one where a peripheral decarboxylase inhibitor has also been used.

Despite one report of universal improvement transiently in all 40 patients following iv injection of levodopa ${ }^{8}$ results of oral therapy have generally been disappointing. McGeer $e t a^{33}$ described only mild benefits in three out of seven patients, while Fleming et $a l^{34}$ reported no effect in three patients. Kimura $e t$ $a l^{10}$ confined their analysis to the improvement in facial mobility in nine cases. No significant benefit occurred in 26 patients treated prophylactically with up to $600 \mathrm{mg}$ levodopa plus benserazide for 6 months when compared with a placebo-treated group. ${ }^{35}$ No adverse psychiatric effects were reported in any of these studies.

Apart from increased anxiety in one patient and potentiation of pre-existing dyskinesia in two others, we encountered no significant complications during levodopa therapy. However, beneficial effects were disappointing. Only one patient, the 26 year old man, made an unequivocally complete recovery. One other (PW) relapsed, implying the presence of underlying Parkinson's disease. In only three of the other eight from whom the offending drug was withdrawn was there a significant functional improvement after up to 39 months, some or all of which could have been attributable to withdrawal rather than levodopa. In only two cases, who continued receiving neuroleptic medication, could benefit reasonably be ascribed to levodopa.

Perhaps of greater significance is the fact that, of 21 patients with disabling NIPS, only two (JS, HY) have had complete resolution, and 19 remain incapacitated despite our management strategies. This naturally questions the prevailing assumption about reversibility of NIPS implicit in the simple mechanism of pharmacological antagonism.

Prolonged delay for up to 18 months in resolution of NIPS following drug withdrawal is well described, ${ }^{36}$ but it has been estimated ${ }^{37}$ that only about $1 \%$ of cases fail to remit and that these few cases were likely to have concomitant Parkinson's disease as well. However, most of our patients remained Parkinsonian despite discontinuation of the apparent cause and use of anti-Parkinsonian drugs.

This experience is similar to that of Stephen and Williamson, ${ }^{19}$ who reported that only $66 \%$ of their 48 NIPS cases resolved completely, within a mean period of 7 weeks and all within 36 weeks, but that $11 \%$ persisted despite stopping the offending drug 18 months earlier. Amongst the 20 patients still alive after a mean interval of 41 months, four $(20 \%)$ had 
experienced remission of NIPS followed by the subsequent development of Parkinson's disease. ${ }^{38}$ However, it should be noted that these patients had a mean age of 80 years (range 71-92) including $60 \%$ with mental impairment, and were exposed to neuroleptics for 1-72 months (mean 21) (J Wilson, personal communication), so the authors' conclusions may not be applicable to a younger group of psychiatric patients such as the subjects of the present report. ${ }^{39}$

Post mortem examination of two patients, in whom remission of NIPS following drug withdrawal had been established, identified histological and biochemical features of idiopathic Parkinsonism including the presence of Lewy bodies. ${ }^{40}$ Since patients with NIPS do not show any clear dose-response correlation, individual susceptibility must play an important part. This susceptibility may depend upon the integrity of the nigro-striatal pathways and those who develop NIPS might be at greater risk of developing idiopathic Parkinsonism as the normal ageing process continues. Positron emission tomography using fluorodopa and D-2 receptor ligands might help to clarify these points.

\section{References}

1 Ayd FJ. A survey of drug-induced extrapyramidal reactions. JAMA 1961;175:1054-60.

2 Mindham RHS. Assessment of drug-induced extrapyramidal reactions and of drugs given for their control. Br J Clin Pharmacol 1976;Suppl:395-400.

3 McLelland HA. Discussion on assessment of drug-induced extrapyramidal reactions. Br J Clin Pharmacol 1976;Suppl:401-3.

4 Johnson DAW. Prevalence and treatment of drug-induced extrapyramidal symptoms. Br J Psychiatry 1978;132:27-30.

5 Curson DA, Barnes TRE, Bamber RW, Platt SD, Hirsch SR, Duffy JC. Long-term depot maintenance of chronic schizophrenic out-patients: the seven year follow-up of the MRC fluphenazine/placebo trial III. Relapse postponement or relapse prevention? The implications for long-term outcome. Br J Psychiatry 1985;146:474-80.

6 Crow TJ, MacMillan JF, Johnson AJ, Johnstone EC. The Northwick Park study of first episodes of schizophrenia II. A randomised controlled trial of prophylactic neuroleptic treatment. Br J Psychiatry 1986;148:120-7.

7 Marsden CD, Mindham RHS, Mackay AVP. Extrapyramidal movement disorders produced by antipsychotic drugs. In: Bradley PB, Hirsch SR, eds. The Psychopharmacology and Treatment of Schizophrenia. Oxford: Oxford University Press, 1986:340-402.

8 Bruno A, Bruno SC. Effects of L-dopa on pharmacological Parkinsonism. Acta Psychiatr Scand 1966;42:264-71.

9 Yaryura-Tobias JA, Wolpert A, Dana L, Merlis S. Action of L-dopa in drug induced extrapyramidalism. Dis Nerv Syst 1970;31:60-63.

10 Kimura N, Tsukue I. L-dopa therapy in drug-induced Parkinsonism evaluated by the method measuring the facial expression. Hiroshima J Med Sci 1971;20:55-63.

11 Yaryura-Tobias JA, Diamond B, Merlis S. The action of L-dopa on schizophrenic patients (a preliminary report). Curr Ther Res 1970;12:528-31.

12 Angrist B, Sathananthan G, Gershon S. Behavioural effects of L-dopa in schizophrenic patients. Psychopharmacologia (Berlin) 1973;31:1-12.

13 Hardie RJ, Lees AJ, Stern GM. Sustained levodopa therapy in tardive dyskinesia. J Neurol Neurosurg Psychiatry 1983;46:685.

14 Alpert M, Friedhoff AJ. Receptor sensitivity modification in the treatment of tardive dyskinesia. Clin Pharmacol Ther 1976;19:103.

15 Marsden CD, Schachter M. Assessment of extrapyramidal disorders. Br J Clin Pharmacol 1981;11:129-51.

16 Freyhan FA. Psychomotility and parkinsonism in treatment with neuroleptic drugs. Arch neurol Psychiatr 1957;78:465-72.

17 Rogers D. The motor disorder of severe psychiatric illness: a conflict of paradigms. Br J Psychiatry 1985;147:221-32.

18 Hausner RS. Neuroleptic-induced parkinsonism and Parkinson's disease: differental diagnosis and treatment. J Clin Psychiatry 1983;44:13-16.

19 Stephen PJ, Williamson J. Drug-induced Parkinsonism in the elderly. Lancet 1984;ii:1082-3.

20 Kataria M, Traub M, Marsden CD. Extrapyramidal side-effects of metoclopramide. Lancet 1978;2:1254-5.

21 Chouza C, Scaramelli A, Caamano JL, Demedina O, Aljanati R, Romero S. Parkinsonism, tardive dyskinesia, akathisia, and depression induced by flunarizine. Lancet 1986;i:1303-4.

22 Pall HS, Williams AC. Extrapyramidal disturbances caused by inappropriate prescribing. Br Med J 1987;295:30-31.

23 Micheli F, Pardal MF, Gatto J, et al. Flunarizine- and cinnarizine-induced extrapyramidal reactions. Neurology 1987;37:881-4.

24 Mutch WJ, Dingwall-Fordyce I, Downie AW, Paterson JG, Roy SK. Parkinson's disease in a Scottish city. $\mathrm{Br}$ Med J 1986;292:534-6

25 McLelland HA, Blessed G,Bhate S, Ali N, Clarke PA. The abrupt withdrawal of antiparkinsonian drugs in schizophrenic patients. Br J Psychiatry 1974;124:151-9.

26 Mindham RHS, Gaind R, Anstee BH, Rimmer L. Comparison of amantadine, orphenadrine, and placebo in the control of $\infty$ phenothiazine-induced Parkinsonism. Psychol Med 1972 2:406-413.

27 Leff JP, Wing JK. Trial of maintenance therapy in schizophrenia Br Med J 1971;3:599-604.

28 Hirsch SR, Gaind R, Rohde PD, Stevens BC, Wing JK. Out patient maintenance of chronic schizophrenic patients with long-acting fluphenazine: double-blind placebo trial. $\mathrm{Br} \mathrm{Med}$ 1973;1:633-7.

29 Inanaga K, Inoue K, Tachibana H, Oshma M, Kotorii T. Effec of L-dopa in schizophrenia. Folia Psychiatr et Neurol 1972;26:145-57.

30 Garfinkel PE, Stancer HC. L-Dopa and schizophrenia. Can Psychiat Assoc J 1976;21:27-29.

31 Ogura C, Kishimoto A, Nakao T. Clinical effects of L-dopa on schizophrenia. Curr Ther Res 1976;20:308-18.

32 Bunney WE, Murphy DL, Brodie HKH, Goodwin FK. L-DOPA in depressed patients. Lancet 1970;i:352.

33 Davidson M, Keefe RSE, Mohs RC, et al. L-Dopa challenge and relapse in schizophrenia. Am J Psychiatry 1987;144:934-8.

34 Chouinard G, Annable L, Mercier P, Turnier L. Long-term effects of L-dopa and procyclidine on neuroleptic-induced extrapyramidal and schizophrenic symptoms. Psychopharmacol Bull 1987;23:221-6.

35 McGeer PL, Boulding JE, Gibson WC, Foulkes RG. Drug-induced extrapyramidal reactions: treatment with diphenhydramine hydrochloride and dihydroxyphenylalanine. JAMA 1961;177:666-70.

36 Fleming $\mathbf{P}$, Makar H, Hunter KR. Levodopa in drug-induced extrapyramidal disorders. Lancet 1970;ii: 1186.

37 Klawans HL, Bergen D, Bruyn GW. Prolonged drug-induced Parkinsonism. Confinia Neurologica 1973;35:368-77.

38 Marsden CD, Jenner P. The pathophysiology of extrapyramidal side-effects of neuroleptic drugs. Psychol Med 1980;10:55-72.

39 Wilson JA, Primrose WR. Drug induced parkinsonism. Lancet 1986;ii:957.

40 Rajput AH, Rozdilsky B, Hornykiewicz O, Shannak K, Lee T, Seeman P. Reversible drug-induced parkinsonism: clinicopathologic study of two cases. Arch Neurol 1982;39:644-6. 